\title{
The value of radiotherapy in breast cancer patients with isolated ipsilateral supraclavicular lymph node metastasis without distant metastases at diagnosis: a retrospective analysis of Chinese patients
}

\author{
This article was published in the following Dove Press journal: \\ OncoTargets and Therapy \\ 15 February 2014 \\ Number of times this article has been viewed
}

\author{
San-Gang $\mathrm{Wu}^{1, *}$ \\ Jia-Yuan Sun ${ }^{2, *}$ \\ Juan Zhou ${ }^{3, *}$ \\ Feng-Yan $\mathrm{Li}^{2}$ \\ Qin Lin' \\ Huan-Xin $\operatorname{Lin}^{2}$ \\ Zhen-Yu He ${ }^{2}$ \\ 'Xiamen Cancer Center, Department \\ of Radiation Oncology, the First \\ Affiliated Hospital of Xiamen \\ University, Xiamen, People's Republic \\ of China; ${ }^{2}$ Sun Yat-sen University \\ Cancer Center, State Key Laboratory \\ of Oncology in South China, \\ Department of Radiation Oncology, \\ Collaborative Innovation Center of \\ Cancer Medicine, Guangzhou, People's \\ Republic of China; ${ }^{3}$ Xiamen Cancer \\ Center, Department of Obstetrics \\ and Gynecology, the First Affiliated \\ Hospital of Xiamen University, \\ Xiamen, People's Republic of China \\ *These authors contributed equally \\ to this work
}

Correspondence: Zhen-Yu He Sun Yat-sen University Cancer Center, State Key Laboratory of Oncology in South China, Department of Radiation Oncology, Collaborative Innovation Center of Cancer Medicine, 65I Dongfeng Road East, Guangzhou 510060, People's Republic of China

Tel +862087343543

Fax +86 2087343392

Email hezhy@sysucc.org.cn
Background: The purpose of this study was to investigate the prognosis of ipsilateral supraclavicular lymph node metastasis (ISLM) without evidence of distant metastases at diagnosis in Chinese women with breast cancer and to elucidate the clinical value of adjuvant radiotherapy.

Methods: We performed a retrospective analysis of clinical data for 39 patients with ISLM from breast cancer without distant metastasis at diagnosis. Combined modality therapy, consisting of neoadjuvant chemotherapy, surgery, and adjuvant chemotherapy with or without adjuvant radiotherapy, was offered to the patients.

Results: The patients in this study accounted for $1 \%$ of all breast cancer patients treated during the same time period. The median follow-up was 35 months. The 5-year locoregional recurrencefree survival, distant metastasis-free survival, disease-free survival (DFS), and overall survival (OS) were $57.3 \%, 42.3 \%, 34.4 \%$, and $46.2 \%$, respectively. Twenty-three patients received postoperative adjuvant radiotherapy. However, there was no significant difference in the 3-and 5 -year locoregional recurrence-free survival ( $P=0.693)$, ISLM-free recurrence $(P=0.964)$, distant metastasis-free survival ( $P=0.964)$, DFS $(P=0.234)$, and OS $(P=0.329)$ rates between the groups of patients who received or did not receive adjuvant radiotherapy $(P=0.840)$. No significant difference in the 3-year locoregional control rate $(P=0.900)$ was found between patients who were treated with adjuvant radiotherapy at $\leq 50 \mathrm{~Gy}$ and $>50 \mathrm{~Gy}$. Univariate analysis showed that clinical tumor size stage and age were prognostic factors that impacted DFS and OS.

Conclusion: Combined modality treatment may achieve satisfactory efficacy in Chinese women with ISLM from breast cancer without distant metastasis at the time of diagnosis, suggesting that ISLM might be considered a curable locoregional disease. Adjuvant radiotherapy did not, however, improve the results of these patients.

Keywords: prognosis, breast cancer, supraclavicular lymph node-metastasis, radiotherapy

\section{Introduction}

Breast cancer is one of the most common malignant tumors in women and, recently, its incidence has been increasing steadily, accounting for around $29 \%$ of all new cases of cancer in females; ${ }^{1}$ approximately $19 \%$ of cancers in Chinese females are breast cancers. ${ }^{2}$ With advancements in screening and diagnosis methods, more cases of early-stage breast cancer can be detected. At the first clinic visit, only a small proportion of patients are diagnosed with ipsilateral supraclavicular lymph node metastasis 
(ISLM) without distant metastasis, and these account for $1 \%-4 \%$ of all cases of breast cancer. ${ }^{3}$

A previous report has shown that the 5-year survival rate of patients with ISLM at the time of diagnosis is only 5\%-34\% (median 18\%). ${ }^{4}$ Therefore, ISLM has been considered a sign of distant metastasis. The fifth edition of the Union for International Cancer Control (UICC)/American Joint Committee on Cancer (AJCC) breast cancer staging system published in 1998 classified patients with ISLM from breast cancer as stage M1 (clinical stage IV). ${ }^{5}$ However, Brito et a ${ }^{6}$ reported in 2001 that the prognosis of breast cancer patients with ISLM following combined modality therapy was better than other patients at clinical stage IV (M1) and was similar to that of stage IIIB patients with locally advanced breast cancer (T4N0-3M0 or T1-4N3M0 in UICC/AJCC TNM staging), suggesting that ISLM might be a locoregional disorder warranting curative-intent therapy. Based on the above study, the sixth edition of the UICC/AJCC staging system for breast cancer, published in 2002, classified breast cancer patients with ISLM as pN3 (IIIc stage). ${ }^{7}$ Brito et al's study was not randomized, however, and was limited by its small sample size and retrospective nature. ${ }^{6}$ Therefore, the reliability of the study remains questionable.

Combined modality therapy is currently considered essential for treating breast cancer patients with ISLM at diagnosis. Locoregional therapy directed toward the supraclavicular region is also an integral part of the treatment approach. Due to the special anatomic location of supraclavicular lymph nodes, it is difficult for breast cancer patients with ISLM to undergo curative lymph node dissection. ${ }^{8}$ For this reason, radiotherapy has become the major locoregional therapy approach for ISLM. At present, radiotherapy is an integral part of combined modality therapy for locally advanced breast cancer; ${ }^{9-11}$ however, the value of radiotherapy in breast cancer patients with ISLM at diagnosis remains controversial. Therefore, in this study, we retrospectively analyzed the prognosis of Chinese breast cancer patients with ISLM at the time of diagnosis and evaluated the value of adjuvant radiotherapy in this patient population.

\section{Materials and methods}

\section{Subjects and inclusion criteria}

We retrospectively analyzed data for 3,759 patients diagnosed with breast cancer treated at the Sun Yat-sen University Cancer Center (SYSUCC), Guangzhou, People's Republic of China from January 1998 to December 2007. In 1998, SYSUCC began to adopt a multidisciplinary approach for the diagnosis and treatment of major malignancies so patients could receive an optimal treatment adapted to their condition. The long-term follow-up of many cancers, including breast cancer, have reached good results in the People's Republic of China. The subjects were selected based on the following criteria: unilateral breast cancer and metastasis in ipsilateral supraclavicular lymph nodes confirmed by pathology, and no evidence of distant metastasis. A total of 39 patients (1.0\%) who met the above criteria were included in the study. Patients underwent combined modality therapy consisting of neoadjuvant chemotherapy, surgery, and adjuvant chemotherapy, with or without radiotherapy. In most cases, an anthracycline- or taxane-based regimen was adopted in neoadjuvant and adjuvant chemotherapy. The patients provided written informed consent for use of their medical records for research purposes and the study protocol was approved by the ethics committee of SYSUCC.

Before chemotherapy, each patient underwent a staging work-up that consisted of a clinical history, physical examination, bilateral mammography, chest computed tomography (CT) scan, ultrasonography of the liver, nuclear bone scan, and biopsies of the breast to document invasive disease.

\section{Treatment}

Neoadjuvant chemotherapy was given initially to reduce tumor burden in patients with ISLM, and to reduce the incidence of distant metastasis. Following pathologic confirmation, all patients underwent neoadjuvant chemotherapy, with a median of three cycles (range, two to six cycles). Eighteen subjects $(46.2 \%)$ were treated with fluorouracil and doxorubicin or epidoxorubicin and cyclophosphamide, 19 (48.6\%) with doxorubicin or epidoxorubicin and paclitaxel or docetaxel, one (2.6\%) with docetaxel, doxorubicin, and cyclophosphamide, and one $(2.6 \%)$ with cyclophosphamide, methotrexate, and fluorouracil. The neoadjuvant chemotherapy regimen was not statistically different between patients with and without adjuvant radiotherapy (Table 1).

ISLM were not indications for breast-conserving surgery in SYSUCC; therefore, all patients received mastectomy after neoadjuvant chemotherapy. Level I-II axillary lymph node dissection was performed in all patients, among whom, 13 (33.3\%) received level III axillary lymph node dissection, 12 (92.3\%) developed metastases in level III lymph nodes, and only one $(7.7 \%)$ experienced no metastases in level III lymph nodes. None of the patients underwent ipsilateral supraclavicular lymph node dissection.

Thirty-eight patients $(97.4 \%)$ received postoperative adjuvant chemotherapy with a median of four cycles (range, two to six cycles), among whom, 17 (43.6\%) were 
Table I Clinical characteristics of patients

\begin{tabular}{|c|c|c|c|c|}
\hline \multirow[t]{2}{*}{ Characteristic } & \multirow[t]{2}{*}{$\mathbf{n}$} & \multicolumn{2}{|l|}{ PMRT } & \multirow[t]{2}{*}{$P$-value } \\
\hline & & None (n) & Yes (n) & \\
\hline \multicolumn{5}{|l|}{ Age (years) } \\
\hline$\leq 35$ & 9 & 3 & 6 & \multirow[t]{2}{*}{0.593} \\
\hline$>35$ & 30 & 13 & 17 & \\
\hline \multicolumn{5}{|l|}{ Menstrual status } \\
\hline Premenopausal & 27 & 12 & 15 & \multirow[t]{2}{*}{0.515} \\
\hline Postmenopausal & 12 & 4 & 8 & \\
\hline \multicolumn{5}{|c|}{ Clinical tumor size stage } \\
\hline cTI & 4 & I & 3 & \multirow[t]{4}{*}{0.803} \\
\hline cT2 & 10 & 4 & 6 & \\
\hline сT3 & 11 & 4 & 7 & \\
\hline $\mathrm{cT} 4$ & 14 & 7 & 7 & \\
\hline \multicolumn{5}{|l|}{ Pathologic T stage } \\
\hline уто & 1 & I & 0 & \multirow[t]{5}{*}{0.777} \\
\hline yTI & 9 & 4 & 5 & \\
\hline$y \top 2$ & 17 & 7 & 10 & \\
\hline yТ3 & 6 & 2 & 4 & \\
\hline yТ4 & 6 & 2 & 4 & \\
\hline \multicolumn{5}{|c|}{ Pathologic nodal stage } \\
\hline yNO & 3 & 2 & 1 & \multirow[t]{4}{*}{0.693} \\
\hline yNI & 8 & 4 & 4 & \\
\hline$y \mathrm{~N} 2$ & 5 & 2 & 3 & \\
\hline yN3 & 23 & 8 & 15 & \\
\hline \multicolumn{5}{|l|}{ ER status } \\
\hline Negative & 17 & II & 6 & \multirow[t]{2}{*}{$0.008^{*}$} \\
\hline Positive & 22 & 5 & 17 & \\
\hline \multicolumn{5}{|l|}{ PR status } \\
\hline Negative & 20 & 9 & 11 & \multirow[t]{2}{*}{0.605} \\
\hline Positive & 19 & 7 & 12 & \\
\hline \multicolumn{5}{|l|}{ Her2 status } \\
\hline Negative & 21 & 8 & 13 & \multirow[t]{2}{*}{0.688} \\
\hline Positive & 18 & 8 & 10 & \\
\hline
\end{tabular}

Notes: $*$ Values of $P<0.05$ were considered to indicate a significant difference between the PMRT and non-PMRT groups. The $\chi^{2}$ and Fisher's exact probability tests were used to compare the differences between the groups of patients who received/did not receive PMRT.

Abbreviations: PMRT, post-mastectomy radiation therapy; $\mathrm{cT}$, clinical tumor size stage; $y \mathrm{~T}$, tumor size after neoadjuvant chemotherapy; $\mathrm{yN}$, status of axillary lymph node after neoadjuvant chemotherapy; ER, estrogen receptor; PR, progesterone receptor; Her2, human epidermal growth factor receptor-2; n, number.

treated with fluorouracil and doxorubicin or epidoxorubicin and cyclophosphamide, 19 (48.6\%) with doxorubicin or epidoxorubicin and paclitaxel or docetaxel, one $(2.6 \%)$ with docetaxel, doxorubicin, and cyclophosphamide, and one $(2.6 \%)$ with cyclophosphamide, methotrexate, and fluorouracil. The adjuvant chemotherapy regimen was not statistically different between patients with and without adjuvant radiotherapy (Table 1 ).

All patients were recommended for adjuvant radiotherapy after adjuvant chemotherapy, but due to economic and social factors $16(41.0 \%)$ did not receive adjuvant radiotherapy, whereas 23 (59.0\%) were treated with adjuvant radiotherapy. The clinicopathological data of patients in both groups are shown in Table 1. The target region of patients who received adjuvant radiotherapy included the ipsilateral chest wall and supra- and infraclavicular (level III axillary lymph nodes) lymph drainage regions. The axillary and internal mammary lymph nodes were not irradiated. Twenty patients were treated with a CT-based, three-dimensional conformal technique, and three patients received conventional external beam radiation therapy. Typically, 46-50 Gy was delivered in 23-25 fractions to the ipsilateral chest wall and lymph drainage regions. The median dose of radiotherapy was 50 Gy in 25 fractions (range 46-50 Gy). The chest wall was treated with tangential fields using $6 \mathrm{MV}$ photons. The supra-and infraclavicular lymph drainage regions with $6 \mathrm{MV}$ photons were combined with a $12-15 \mathrm{MeV}$ ray. Seven patients (18.0\%) received a radiation boost in the metastatic supraclavicular lymph node region. The median irradiation boost was $10 \mathrm{~Gy}$ (range, 10-24 Gy).

A total of 23 estrogen receptor-positive (positive immunostaining of $\geq 10 \%$ malignant cells) patients (59.0\%) were treated with endocrine therapies (tamoxifen) after postoperative chemotherapy and/or radiotherapy. No trastuzumab (Herceptin; Roche, Basel, Switzerland) was used for the human epidermal growth factor receptor-2 (Her2)-positive patients.

\section{Follow-up and study end points}

Follow-up was scheduled every 3-6 months from the first day after surgery. The primary study end points were locoregional recurrence-free survival (LRFS) (locoregional recurrence \pm distant metastasis) and overall survival (OS). Secondary end points included distant metastasis-free survival (DMFS) and disease-free survival (DFS). The survival condition of the patients was obtained by reviewing their medical records or by direct follow-up via telephone or mail. To detect local or distant relapse, clinical follow-up was carried out, which included recording patient's history, physical examination, laboratory tests of complete blood counts, and liver function test, chest radiography, mammography, breast and abdominopelvic ultrasonography, and bone scans. In addition, a CT scan or a fluorine-18-fluorodeoxyglucose (18F-FDG) positron emission tomography/computed tomography (PET/CT) scan was carried out if necessary.

Locoregional recurrence refers to pathologically confirmed relapse in the ipsilateral chest wall, supra- and infraclavicular fossa, axillary area, or internal mammary region. Distant metastasis was confirmed by two types of medical imaging (and pathology if needed) to confirm that cancer had spread to distant sites away from the locoregional recurrence sites. DFS refers to patients without locoregional or 
distant recurrence. Breast cancer-related death was defined as the mortality end point. Different examinations were used to confirm potential metastases at distinct sites: bone metastasis required bone scan and magnetic resonance imaging; lung metastasis usually was identified by repeated chest radiograph, followed by chest CT or PET/CT confirmation; for liver metastasis, ultrasound was generally used at follow-up, followed by magnetic resonance imaging or PET/CT if an abnormality was observed.

\section{Statistical analysis}

All data were analyzed using the SPSS statistical software package (v 16.0; IBM Corporation, Armonk, NY, USA). The $\chi^{2}$ and Fisher's exact probability tests were used to analyze the differences between qualitative data. The Kaplan-Meier method was employed to compare survival rates. The statistical significance was determined using the logrank test. The statistical significance level was set at $P<0.05$.

The prognostic factors affecting survival were analyzed, including age, menopausal status, level III axillary lymph node dissection, primary tumor size at first diagnosis (cT), tumor size after neoadjuvant chemotherapy (yT), status of axillary lymph node after neoadjuvant chemotherapy $(\mathrm{yN})$, estrogen receptor status, progesterone receptor status, Her2 status, and adjuvant radiotherapy. Age was assessed as $\leq 35$ years of age versus $>35$ years of age, since a study has suggested that breast cancer patients younger than 35 years have markedly different biological characteristics with worse prognosis than older patients. ${ }^{12}$ Similar results have also been observed in Chinese breast cancer patients. ${ }^{13}$ Multivariate analysis was not performed in this study due to the relatively small number of subjects.

\section{Results}

\section{Characteristics of patients}

A total of 39 patients, who were diagnosed with ISLM with no evidence of distant metastases at diagnosis and accounting for $1.0 \%$ of 3,759 newly diagnosed breast cancer patients, were included in this study. In the 39 patients, the median age of onset of the disease was 47 years (range, 29-65 years). Thirty-eight cases $(97.4 \%)$ were diagnosed with invasive ductal carcinoma and one case $(2.6 \%)$ with invasive micropapillary carcinoma. The clinical characteristics of the patients are shown in Table 1.

\section{Therapeutic outcomes}

The histopathological analysis after surgery showed that the tumor stage after neoadjuvant chemotherapy was reduced to yT1-2 in $13(33.3 \%)$ of the 25 patients (64.1\%) initially classified as cT 3-4 stage. The tumor stage of one patient $(2.6 \%)$ was reduced to yT0 from cT1 after neoadjuvant chemotherapy. The status of axillary lymph node after neoadjuvant chemotherapy was reduced to zero in three patients (7.7\%).

The median follow-up duration for all the 39 patients and for the surviving patients was 35 months (range, 10-138 months) and 64 months (range, 24-138 months), respectively. Locoregional recurrence occurred in 14 cases $(35.9 \%)$, seven of whom had recurrences in the chest wall alone, three in the supraclavicular fossa alone, one in the axillary lymph nodes alone, two in both supraclavicular fossa and axillary lymph nodes, and one in both the chest wall and axillary lymph nodes. Twenty-five patients (64.1\%) developed distant metastases, mostly involving the bone, lung, and liver. Twenty-one patients (53.9\%) died during the follow-up period. For all patients, the 3- and 5-year LRFS rates were 67.8\% and $57.3 \%$, respectively, and the 3- and 5-year DMFS rates were $45.8 \%$ and $42.3 \%$, respectively. The 3 - and 5-year DFS rates were $40.7 \%$ and $34.4 \%$, respectively, and the 3- and 5-year OS rates were $55.9 \%$ and $46.2 \%$, respectively (Figure 1 ).

\section{Analysis of prognostic factors}

Univariate prognostic analysis showed that cT stage $(P=0.002)$ and age $(P=0.049)$ were both significantly correlated with DFS. The univariate prognostic analysis also showed that cT stage $(P=0.002)$ and age $(P=0.0008)$ were both significantly correlated with OS (Table 2 ).

\section{Effects of radiotherapy on prognosis}

Twenty-three patients received postoperative radiotherapy; however, there was no significant difference in the 3-and 5-year LRFS rates, ipsilateral supraclavicular recurrence, and DMFS, DFS, or OS rates between the groups that were and were not treated with radiotherapy (Table 3). Dose escalation of radiotherapy also failed to enhance the locoregional control. The 3-year locoregional control rates were 78.3\% and $83.3 \%$ when $\leq 50$ Gy and $>50$ Gy were applied for supraclavicular lymph nodes, respectively $(P=0.900)$.

\section{Discussion}

Based on the retrospective analysis of the prognosis and effect of adjuvant radiotherapy in 39 cases of newly diagnosed Chinese female patients with ISLM from breast cancer without evidence of distant metastases, we conclude that a good survival rate may be achieved by combined modality therapy including neoadjuvant therapy, surgery, and adjuvant 
A

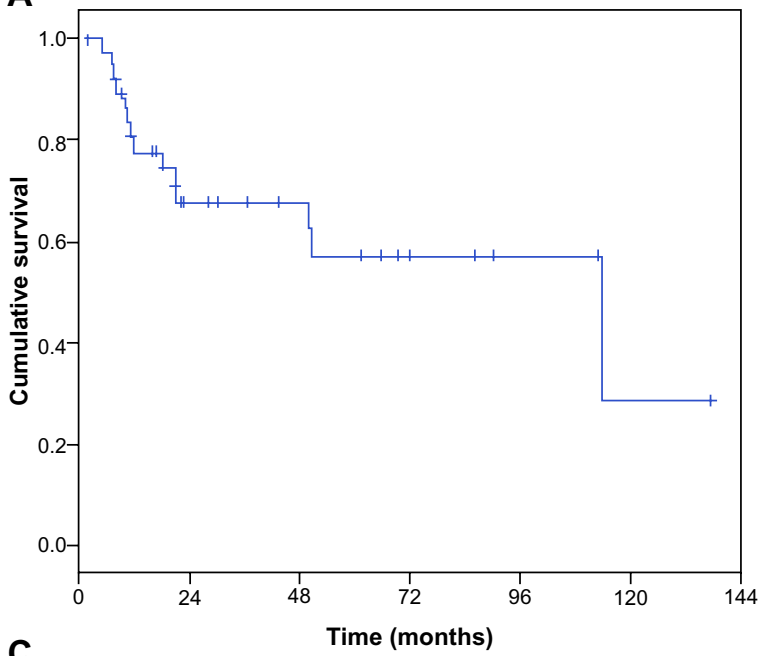

C

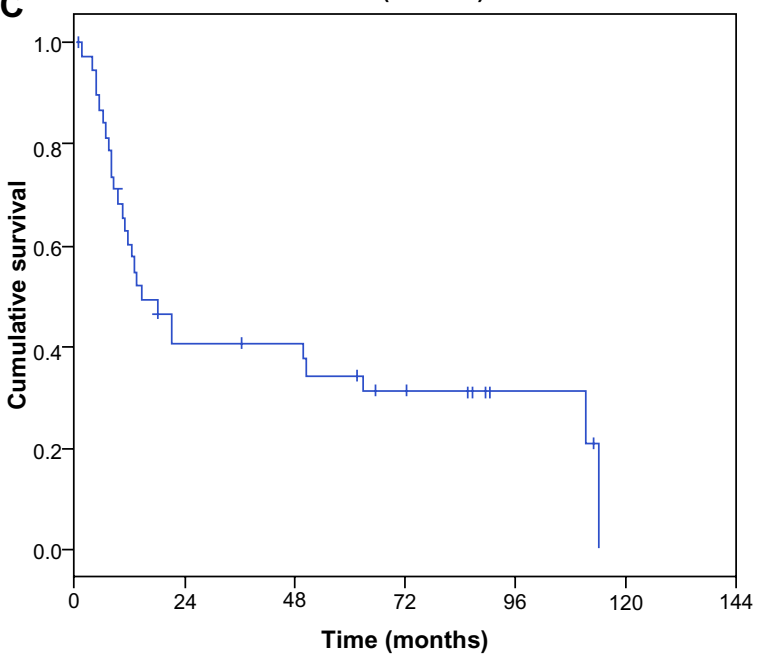

B

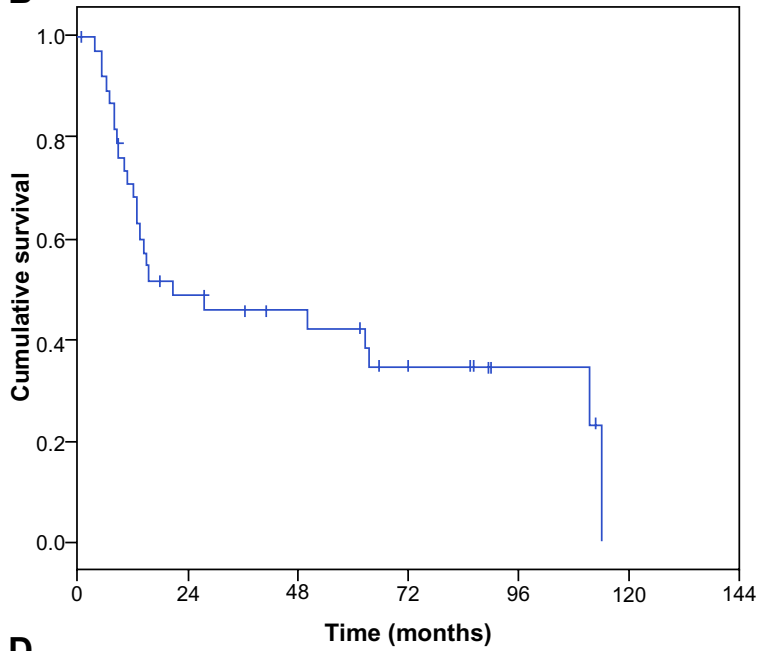

D

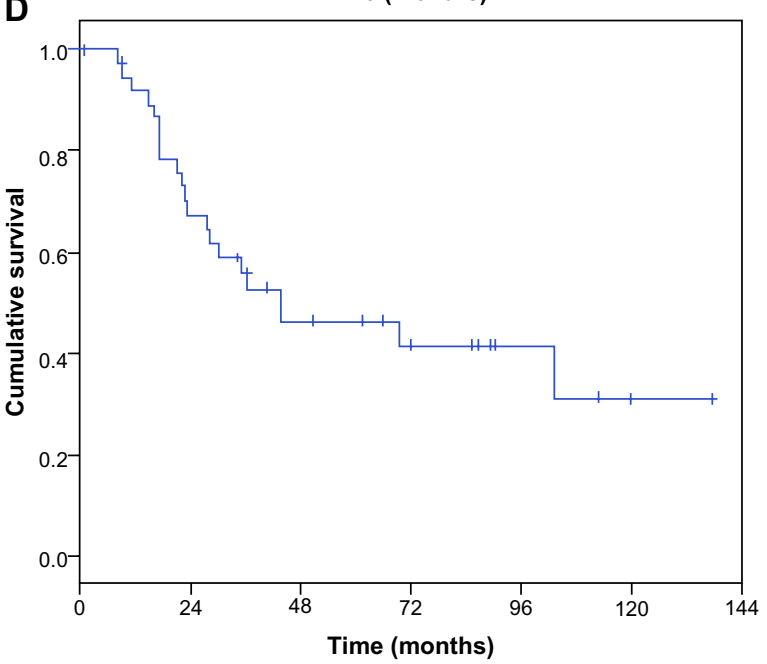

Figure I Cumulative survival of patients.

Notes: (A) Locoregional recurrence-free survival curve; (B) distant metastasis-free survival curve; (C) disease-free survival curve; and (D) overall survival curve of patients.

chemotherapy, with or without adjuvant radiotherapy. However, radiotherapy and dose escalation have no beneficial effects on patient survival.

Consistent with a previous report, ${ }^{3}$ the patients with ISLM from breast cancer without evidence of distant metastases accounted for $1.0 \%$ of all patients during the same time period. Locoregional therapy, including radiotherapy or surgery along with radiotherapy, was previously adopted in breast cancer with ISLM, but the prognosis was somewhat discouraging. ${ }^{14,15}$ The majority of patients developed distant metastases within 1 year, which might be related to a lack of availability of an appropriate systemic drug therapy (eg, chemotherapy along with endocrine therapy). The report from Brito et $\mathrm{al}^{6}$ directly resulted in the modification of the UICC/AJCC breast cancer staging system. Similar to previous reports, ${ }^{16-18}$ our study has shown that the 5-year OS rate was $46.2 \%$ when patients received neoadjuvant chemotherapy, surgery, and adjuvant therapy (chemotherapy and endocrine therapy), with or without radiotherapy, which suggests that the change of stage from M1 to N3 for ISLM is also applicable in Chinese women; however, in the present study, the 3-year distant metastasis occurrence rate still exceeded $50 \%$ after combined modality therapy and the 5-year DFS was only $34.4 \%$, indicating that ISLM is a high-risk disease with metastatic potential. It is expected that patients with ISLM will benefit more from the rapid advancement of systemic therapy for breast cancer.

The value of radiotherapy in the treatment of ISLM remains controversial. Based on the results of this study, we conclude that postoperative radiotherapy failed to improve the prognosis of patients with ISLM, including its failure in altering locoregional recurrence, rates of distant metastases, and survival rates. The 3-year LRFS for patients with and without post-mastectomy radiation therapy (PMRT) was $59.1 \%$ and $70.9 \%$, respectively . This may be due to patients with worse prognostic factors. But the correlation of most 
Table 2 Univariate prognostic analysis of survival

\begin{tabular}{|c|c|c|c|c|c|c|}
\hline \multirow[t]{2}{*}{ Characteristic } & \multicolumn{2}{|l|}{ LRFS } & \multicolumn{2}{|l|}{ DFS } & \multicolumn{2}{|l|}{ os } \\
\hline & 5 -year (\%) & $P$-value & 5 -year (\%) & $P$-value & 5 -year (\%) & $P$-value \\
\hline \multicolumn{7}{|l|}{ Age (years) } \\
\hline$\leq 35$ & 85.7 & 0.218 & 22.2 & $0.049 *$ & 22.2 & $0.008^{*}$ \\
\hline$>35$ & 51.2 & & 38.0 & & 53.7 & \\
\hline \multicolumn{7}{|l|}{ Menstrual status } \\
\hline Premenopausal & 60.8 & $0.74 I$ & 33.3 & 0.366 & 40.3 & 0.064 \\
\hline Postmenopausal & 50.3 & & 37.0 & & 61.4 & \\
\hline \multicolumn{7}{|c|}{ Clinical tumor size stage } \\
\hline cTI-cT2 & 76.9 & 0.086 & 64.3 & $0.002^{*}$ & 78.6 & $0.002^{*}$ \\
\hline cT3-cT4 & 37.2 & & 15.7 & & 36.1 & \\
\hline \multicolumn{7}{|l|}{ Pathologic T stage } \\
\hline уТ0-ут2 & 62.8 & 0.343 & 43.9 & 0.055 & 54.6 & 0.095 \\
\hline уТ3-yТ4 & 48.9 & & II.I & & 25.4 & \\
\hline \multicolumn{7}{|c|}{ Pathologic nodal stage } \\
\hline yN0-yN2 & 61.4 & 0.501 & 46.7 & 0.098 & 60.0 & 0.283 \\
\hline yN3 & 59.5 & & 27.3 & & 35.7 & \\
\hline \multicolumn{7}{|l|}{ ER status } \\
\hline Negative & 48.6 & 0.556 & 29.6 & 0.921 & 41.0 & 0.722 \\
\hline Positive & 58.6 & & 34.3 & & 48.5 & \\
\hline \multicolumn{7}{|l|}{ PR status } \\
\hline Negative & 56.9 & 0.790 & 30.1 & 0.802 & 43.5 & 0.986 \\
\hline Positive & 52.5 & & 34.3 & & 47.1 & \\
\hline \multicolumn{7}{|l|}{ Her2 status } \\
\hline Negative & 48.1 & 0.139 & 39.7 & 0.544 & 55.6 & 0.258 \\
\hline Positive & 78.6 & & 27.8 & & 36.7 & \\
\hline \multicolumn{7}{|l|}{ PMRT } \\
\hline None & 59.1 & 0.693 & 42.8 & 0.329 & 46.1 & 0.840 \\
\hline Yes & 56.7 & & 29.8 & & 46.6 & \\
\hline
\end{tabular}

Note: $* P<0.05$ indicates a significant difference.

Abbreviations: LRFS, locoregional recurrence-free survival; DFS, disease-free survival; OS, overall survival; cT, clinical tumor size stage; yT, tumor size after neoadjuvant chemotherapy; $y \mathrm{~N}$, status of axillary lymph node after neoadjuvant chemotherapy; ER, estrogen receptor; PR, progesterone receptor; Her2, human epidermal growth factor receptor-2; PMRT, post-mastectomy radiation therapy.

clinicopathological factors between patients with and without PMRT was not significant. Meanwhile, high-dose locoregional radiation was not able to enhance the locoregional control of the patients significantly. These results are similar to those of Ogino et al; ${ }^{17}$ however, other studies conducted by Brito et al, ${ }^{6}$ Fan et al, ${ }^{19}$ and Huang et al ${ }^{20}$ showed that radiotherapy might improve the prognosis of patients with ISLM, although high-dose ( $>55 \mathrm{~Gy}$ ) radiotherapy failed to further enhance the locoregional control and survival. ${ }^{20,21}$ Despite this significantly worse prognosis disease in the PMRT group, the 3- and 5-year OS for PMRT and non-PMRT groups is similar, suggesting that PMRT could be beneficial in patients, although the sample size of present study was too small for this to be conclusive. Further studies in larger cohorts are necessary to evaluate the clinical value of PMRT in patients with ISLM. There is currently no standard guideline for the radiation dosage for patients with ISLM. It should be noted that brachial plexus injury might be induced by high-dose radiation therapy. ${ }^{22}$ In the present study, $97 \%$ of the patients received neoadjuvant chemotherapy, surgery, and adjuvant chemotherapy with an anthracycline- and/or taxane-based regimen, and the OS rate was found to be similar to that in a previous report. ${ }^{18}$ Due to the different chemotherapy regimens and the heterogeneity of the patient populations in different studies, the analysis on the efficacy of radiotherapy in patients with ISLM might yield varying results.

The prognostic factors affecting survival of the patients remain unclear. Huang et $\mathrm{al}^{20}$ considered a remaining lump after neoadjuvant chemotherapy as a prognostic factor for LRFS and DFS. Ogino et $\mathrm{al}^{17}$ found that carcinoembryonic antigen and cancer antigen 15-3 were prognostic factors for survival. Fan et $\mathrm{l}^{19}$ suggested that the $\mathrm{cT}$ stage and adjuvant radiotherapy were prognostic factors affecting OS. The present study only performed univariate prognostic analysis and our results showed that the cT stage and age were both prognostic factors that impacted DFS and OS. Multivariate analysis was not performed in this study due to the relatively small number of subjects. Prognostic 
Table 3 Effect of radiotherapy on the prognosis of patients

\begin{tabular}{|c|c|c|c|}
\hline \multirow{2}{*}{$\begin{array}{l}\text { Survival } \\
\text { end point }\end{array}$} & \multicolumn{2}{|l|}{ PMRT } & \multirow[t]{2}{*}{$P$-value } \\
\hline & None (\%) & Yes (\%) & \\
\hline \multicolumn{4}{|l|}{ LRFS } \\
\hline 3 years & 70.9 & 59.1 & 0.693 \\
\hline 5 years & 66.2 & 56.7 & \\
\hline \multicolumn{4}{|l|}{ ISRFS } \\
\hline 3 years & 81.8 & 81.8 & 0.964 \\
\hline 5 years & 80.3 & 80.3 & \\
\hline \multicolumn{4}{|l|}{ DMFS } \\
\hline 3 years & 50.6 & 50.6 & 0.234 \\
\hline 5 years & 43.5 & 30.8 & \\
\hline \multicolumn{4}{|l|}{ DFS } \\
\hline 3 years & 51.3 & 34.8 & 0.329 \\
\hline 5 years & 42.8 & 29.8 & \\
\hline \multicolumn{4}{|l|}{ OS } \\
\hline 3 years & 55.3 & 56.5 & 0.840 \\
\hline 5 years & 46.1 & 46.6 & \\
\hline
\end{tabular}

Note: The Kaplan-Meier test was used to compare the differences between the groups of patients who received/did not receive PMRT.

Abbreviations: PMRT, post-mastectomy radiation therapy; LRFS, locoregional recurrence-free survival; ISRFS, ipsilateral supraclavicular recurrence-free survival; DMFS, distant metastasis-free survival; DFS, disease-free survival; OS, overall survival.

factors for LRFS were not identified in our analyses. It is still difficult to pinpoint the optimal prognostic factor(s) due to the small sample sizes in all the aforementioned studies; further studies in larger cohorts are necessary to identify the most significant prognostic factor(s) in breast cancer patients with ISLM.

We acknowledge that our study has several limitations: 1) the conclusions are based on a retrospective analysis of the data for a limited number of subjects with a relatively short follow-up duration. In addition, randomized controlled trials are lacking; and 2) none of the Her2-positive patients were treated with trastuzumab. It is unclear whether trastuzumab has a beneficial effect in such patients and further studies are required to clarify this.

\section{Conclusion}

The results of this study suggest that combined modality treatment may achieve satisfactory efficacy in Chinese women with ISLM from breast cancer without distant metastasis at the time of diagnosis. Taken together, the data suggest that this condition might be considered a curable locoregional disease; however, radiotherapy may not improve the prognosis in this patient population. Since the sample size is too small, further multicenter studies in larger cohorts are needed to confirm this conclusion.

\section{Acknowledgments}

This study was supported by a grant from the Sci-Tech Office of Guangdong Province (No 2008B060 600019), the
Youth Foundation of the First Affiliated Hospital of Xiamen University (No XYY2012005), and the Education Scientific Research Foundation of Young Teachers of Fujian Province (No JB13131).

\section{Disclosure}

The authors report no conflicts of interest in this work.

\section{References}

1. Siegel R, Naishadham D, Jemal A. Cancer statistics, 2013. CA Cancer J Clin. 2013;63(1):11-30.

2. Zhao P, Chen WQ. Annual Report of Cancer Registration in China 2010. Beijing: Military Medical Sciences Press; 2011. [Chinese].

3. Chen SC, Chen MF, Hwang TL, et al. Prediction of supraclavicular lymph node metastasis in breast carcinoma. Int J Radiat Oncol Biol Phys. 2002;52(3):614-619.

4. Greene FL, Page DL, Fleming ID, et al. AJCC Cancer Staging Handbook. 6th ed. New York, NY: Springer; 2002.

5. Hermanek P, Sobin LH, editors. TNM Classification of Malignant Tumours: International Union Against Cancer. 4th ed. New York, NY: Springer; 1987.

6. Brito RA, Valero V, Buzdar AU, et al. Long-term results of combinedmodality therapy for locally advanced breast cancer with ipsilateral supraclavicular metastases: The University of Texas MD Anderson Cancer Center experience. J Clin Oncol. 2001;19(3):628-633.

7. Singletary SE, Allred C, Ashley P, et al. Revision of the American Joint Committee on Cancer staging system for breast cancer. J Clin Oncol. 2002;20(17):3628-3636.

8. Aldridge T, Kusanale A, Colbert S, Brennan PA. Supraclavicular metastases from distant primaries: what is the role of the head and neck surgeon? Br J Oral Maxillofac Surg. 2013;51(4):288-293.

9. Overgaard M, Hansen PS, Overgaard J, et al. Postoperative radiotherapy in high-risk premenopausal women with breast cancer who receive adjuvant chemotherapy. Danish Breast Cancer Cooperative Group 82b Trial. N Engl J Med. 1997;337(14):949-955.

10. Overgaard M, Jensen MB, Overgaard J, et al. Postoperative radiotherapy in high-risk postmenopausal breast-cancer patients given adjuvant tamoxifen: Danish Breast Cancer Cooperative Group DBCG 82c randomised trial. Lancet. 1999;353(9165):1641-1648.

11. Ragaz J, Olivotto IA, Spinelli JJ, et al. Locoregional radiation therapy in patients with high-risk breast cancer receiving adjuvant chemotherapy: 20-year results of the British Columbia randomized trial. J Natl Cancer Inst. 2005;97(2):116-126.

12. Colleoni M, Rotmensz N, Robertson C, et al. Very young women ( $<35$ years) with operable breast cancer: features of disease at presentation. Ann Oncol. 2002;13(2):273-279.

13. Peng R, Wang S, Shi Y, et al. Patients 35 years old or younger with operable breast cancer are more at risk for relapse and survival: a retrospective matched case-control study. Breast. 2011;20(6):568-573.

14. Kiricuta IC, Willner J, Kölbl O, Bohndorf W. The prognostic significance of the supraclavicular lymph node metastases in breast cancer patients. Int J Radiat Oncol Biol Phys. 1994;28(2):387-393.

15. Jackson SM. Carcinoma of the breast - the significance of supraclavicular lymph node metastases. Clin Radiol. 1966;17(2):107-114.

16. Olivotto IA, Chua B, Allan SJ, Speers CH, Chia S, Ragaz J. Long-term survival of patients with supraclavicular metastases at diagnosis of breast cancer. J Clin Oncol. 2003;21(5):851-854.

17. Ogino T, Komoike $\mathrm{Y}$, Ishitobi M, Motomura $\mathrm{K}$, Koyama $\mathrm{H}$, Inaji $\mathrm{H}$. Breast cancer with ipsilateral supraclavicular metastases. Breast $J$. 2011;17(5):555-557.

18. Grotenhuis BA, Klem TM, Vrijland WW. Treatment outcome in breast cancer patients with ipsilateral supraclavicular lymph node metastasis at time of diagnosis: a review of the literature. Eur J Surg Oncol. 2013;39(3):207-212. 
19. Fan Y, Xu B, Liao Y, Yao S, Sun Y. A retrospective study of metachronous and synchronous ipsilateral supraclavicular lymph node metastases in breast cancer patients. Breast. 2010;19(5):365-369.

20. Huang EH, Strom EA, Valero V, et al. Locoregional treatment outcomes for breast cancer patients with ipsilateral supraclavicular metastases at diagnosis. Int J Radiat Oncol Biol Phys. 2007;67(2): 490-496.
21. Park HJ, Shin KH, Cho KH, et al. Outcomes of positron emission tomography-staged clinical N3 breast cancer treated with neoadjuvant chemotherapy, surgery, and radiotherapy. Int J Radiat Oncol Biol Phys. 2011;81(5):e689-e695.

22. Lundstedt D, Gustafsson M, Steineck G, et al. Long-term symptoms after radiotherapy of supraclavicular lymph nodes in breast cancer patients. Radiother Oncol. 2012;103(2):155-160.

\section{Publish your work in this journal}

OncoTargets and Therapy is an international, peer-reviewed, open access journal focusing on the pathological basis of all cancers, potential targets for therapy and treatment protocols employed to improve the management of cancer patients. The journal also focuses on the impact of management programs and new therapeutic agents and protocols on

\section{Dovepress}

patient perspectives such as quality of life, adherence and satisfaction. The manuscript management system is completely online and includes a very quick and fair peer-review system, which is all easy to use. Visit http://www.dovepress.com/testimonials.php to read real quotes from published authors.

\footnotetext{
Submit your manuscript here: http://www.dovepress.com/oncotargets-and-therapy-journal
} 